Article

\title{
Natural changes in a soil of the Mediterranean climate under low agronomic inputs
}

\author{
Antonietta Napolitano ${ }^{1}$ Domenica Villecco ${ }^{2}$ and Luigi Santonicola ${ }^{3}$
}

1 1Researcher of CREA Research Center for vegetable and Ornamental Crops (referent); antonietta.napolitano@crea.gov.it

2 Research Grant of CREA Research Center for vegetable and Ornamental Crops: Domenica.villecco@crea.gov.it

3 Researcher of CREA Research Center for vegetable and Ornamental Crops; luigi.santonicola56@gmail.com.

\begin{abstract}
This study was conducted to evaluate the behavior of nitrate, moisture and organic matter in a soil with low agronomic input. The test was conducted on silty-sandy soil, a temporal variability of the variables in the different seasons was observed in the three theses. The theses were observed in parallel twice a week. Nitrates showed an increase during the summer-autumn season with higher values in the thesis containing organic matter, "bare soil" followed by the thesis "fallow" and finally by the "cultivated" (see below in experimental set up). The humidity was higher in the "bare soil" thesis followed by "fallow" and "cultivated" one during the summer, in winter the "cultivated" showed the lowest humidity compared to the other two theses. The organic matter does not show great variability in the seasons but is higher in the "fallow" thesis followed by "bare soil" and "cultivated" one. The Montecarlo test informed us that organic matter and humidity were autocorrelated within 5-7.5 m of distance (10-15 lag) while nitrates even if they seemed to be not autocorrelated with each other and have a cyclical pattern.
\end{abstract}

Keywords: nitrates; moisture; organic matter.

\section{Introduction}

The nitrogen constitutes on average $1-3 \%$ of the dry substance of mature and fine tissues of plants, $5-6 \%$ of that of young tissues. $95-98 \%$ of nitrogen of soil is in organic form; $2-5 \%$ is present in the soil in ammoniacal form; of this high amount of total nitrogen present in the soil only $1 \%$ can be found in nitric form, that is a chemical form easily absorbable by plants (web site: Azoto nel terreno). Nitrogen $(\mathrm{N})$ is an essential element required for successful of plants growth. It is the main form of the element absorbed by the most plants (Brady et al., 2008). The $\mathrm{N}$ cycle process in the soil-plant system is very complex: fixation, mineralization and nitrification increase available $\mathrm{N}$ for plants, inversely denitrification, volatilization, immobilization, and leaching result in $\mathrm{N}$ losses from the root zone (Nutrient Management 2009). Nitrogen, in its oxidate form, nitrate, represents the most important nutrient source for the plants. This form is easily leached by rain and copious irrigation because it is particularly soluble in water. Mineralization occurs largely through biological activities that are temperature and moisture dependent (Agehara and Warncke, 2005; Stevenson, 1986). Kemmitt et al. (2008) suggested that N mineralization is not regulated by the size, composition, or activity of the soil microbial biomass, rather, an abiological process termed the "regulatory gate" controls the rate-limiting step of $\mathrm{N}$ mineralization. Knowledge of the nitrogen $(\mathrm{N})$ available to crops during the growing season is essential for improving fertilizer-use efficiency and avoiding excess of nitrogen fertilizer supply. When the application rate of nitrogen fertilizer was increased, yield content also 
increased (Liu et al. 2014). High levels of nitrate may further lead to severe pathologies in humans, so cultivating edible crops with low nitrate content is very important (Mensinga et al., 2003). The Joint Expert Committee of the Food and Agriculture (JECFA) Organization of the United Nations/World Health Organization and the European Commission (EC) Scientific Committee on Food have also set an acceptable daily intake for nitrate of 0-3.7 mg $\cdot \mathrm{kg}-1$ body weight (Santamaria et al., 2006). Also, organic matter (OM) content can impact soil N supply (Dharmakeerthi et al., 2005; Subbarao et al., 2006) by influencing the activity of microorganisms and the concentrations of ammonium and nitrates in the soil solution (Delin and Lindén, 2002) found that $\mathrm{N}$ mineralization was controlled by organic matter $(\mathrm{OM})$ and clay content. Soil OM is a heterogeneous mixture of organic compounds with variable molecular weights and physical locations in the soil (e.g., in the soil solution, adsorbed onto clay minerals, on the external or internal surfaces of aggregates). The labile fractions in soil OM containing $\mathrm{N}$ are of greatest relevance, because they are involved in the mineralization-immobilization reactions that control the supply of plantavailable nitrogen (N) (Duxbury et al., 1991; Gregorich et al., 1994; Haynes, 2005). Mineral nitrogen content of soil varies temporally and spatially (Diacono et al.,2012) due to agricultural management history, soil properties and environmental conditions (Luce et al., 2011). Recent studies have shown that $\mathrm{N}$ mineral content determined through biological methods in laboratory, is too high respect to chemical methods, probably it due to sample handling, and to lack of no fast, accurate and serial methods that reflect really field conditions (Benedetti and Sebastiani,1996). The objectives of the present study were: to monitor trend over time of nitrates, organic matter and moisture content of soil in three different agronomical conditions (bare, fallow and cultivated soil) at three different depths during months; to assess spatial and temporal variability of these parameters on linear transect and square as reference parameters to validate the meaning of the observations.

\section{Materials and methods}

\subsection{Site, climate and soil}

The trials reported in the following study have been carried out in the experimental field of the CRA-CAT (Scafati SA, Italy). The local climate consisted of mild winters and hot and rainless summer. The soil wass formed by alluvial deposits mixed with volcanic materials. The soil of the field was classified as Vitric Andosol Calcaric, according to the classification WRB 2006. There were two type A minerals horizons, developed by surface layers modified by agricultural activities (horizon Ap1 and Ap2) (Basile A. and Terribile F., 2008). The soil on which the test was carried out was sandy-silty texture, so it was a well-oxygenated soil that does not suffer from water stagnation during winter (Table1).

Table 1. Characteristics of soil.

\begin{tabular}{cc}
\hline & Characteristics of soil \\
\hline $\mathbf{p H}$ & 8,7 \\
\hline sand & $>75 \%$ \\
\hline silt & $18 \%$ \\
\hline clay & $5-7 \%$ \\
\hline $\mathrm{CaCO}_{3}$ & $8 \mathrm{~g} \mathrm{Kg}^{-1}$ \\
\hline Organic Matter & $17 \mathrm{~g} \mathrm{Kg}^{-1}$ \\
\hline Total Nitrogen & $1,3 \% \mathrm{o}$ \\
\hline
\end{tabular}

\subsection{Experimental set up}

The study was carried out with a frequency of about three days starting from May 2012 to July 2013: the months of the year separated into summer and winter; the months from May to October were considered summer, while the months from November to April were considered winter. The theses studied were bare soil, fallow and cultivated. First 
thesis contained the organic matter deriving from radical residues of turf removed by manual weeding (bare soil), the second thesis was constituted by an uncultivated soil covered by stable sward (fallow) and the last thesis was without vegetation, with low organic matter content due to repeated plowing, without addition of organic matter and mineral fertilizers (cultivated). The samplings were made at three different depths: between 0 and $10 \mathrm{~cm}$ (referred to the depth 10), between 10 and $20 \mathrm{~cm}$ (referred to the depth 20) and between 20 and $30 \mathrm{~cm}$ (referred to the depth 30). The measurements made simultaneously in three theses. Other measurements were made on a square of soil and on consecutive days to see if the spatial variability was different from the temporal variability. Twenty samples collected on the same line in the same day at a distance of $10 \mathrm{~cm}$ for a total of $2 \mathrm{~m}$ in length, the same thing was done for 20 consecutive days on lines parallel to the first at a distance of $10 \mathrm{~cm}$ using a total of $2 \mathrm{~m}$ wide, the samples were taken at a depth of $10 \mathrm{~cm}$, obtaining 400 total samples. Hundred soil samples were collected over soil of $100 \mathrm{~m}$ in length at $0.5 \mathrm{~m}$ away on a linear transept to test the variability in the space of the variables examined. Parameters measured were humidity, nitrates and organic matter. The moisture level achieved in the soil was monitored gravimetrically at $378.15 \mathrm{~K}$ and expressed in percent of dry weight. Nitrates and organic matter were monitored with a UV-Vis spectrophotometer (DU 64 Beckman Coulter S.r.l.), reading at two wavelengths (220 nm and $275 \mathrm{~nm}$ ) according to official method used for clear water with low content of organic substances (Merafina P, 2003). The standard solutions prepared with potassium nitrate at known concentrations of $0,1.3,3,4.5$, and $6 \mathrm{ppm}$.

The organic matter was calculated with the absorbance readings at $275 \mathrm{~nm}$, the spectrophotometric readings measured the organic substance only in terms of comparison between the theses but with the use of appropriate standards they can easily be transformed into absolute values (Albrektienè et al., 2012).

\subsection{Data analysis}

All data were elaborated with free software $\mathrm{R}$ project for statistical computing, version 3.5.1 (R-package used car, PMCMR, conover, sp, gstat, geoR). Normality of distribution of variables was verified by the Shapiro-Wilk test. Since the studied variables resulted non-normally distributed, homoschedasticity was verified by Levene's Test for non-parametric data.

Data homoscedasticity were analyzed using Kruskall-Wallis's test and conover test, adjusted using the Bonferroni method, as post hoc. The comparison for heteroschedastic data was made by Friedman's test and confirmed by Nemeny-Damico-Wolfe-Dunn post hoc test.

For all analysis, a p-value $<0.05$ was significant.

We consider the results of the transept to study spatial variability, computing experimental variogram by Monte Carlo test to calculate spatial autocorrelation of parameters studied (Omodame M., 2012).

\section{Results}

The humidity showed significantly different values in the three theses $(p=0.0000)$ with higher averages in the thesis bare soil $(29.01 \%)$ followed by, fallow $(27.08 \%)$ and cultivated soil (18.16\%).

Naturally the humidity was lower in summer than in winter with an average of $21.40 \%$ and $29.72 \%$ of dry weight of soil respectively $(\mathrm{p}=0.0000$ ).

As showed by Figure 1, during the winter period, the bare soil and fallow theses were not statistically different from each other $(p=1)$; the summer fallow was not different from the winter cultivated $(\mathrm{p}=1)$; during the summer the theses were all statistically different from each other $(p=0.0000)$; during the summer and winter seasons the cultivated thesis has lower values than other theses $(\mathrm{p}=0.0000)$. 
As regards the effect of depth on the soil water content, there was a slight reduction moving from 10 to $30 \mathrm{~cm}(25.34 \%$ at $10 \mathrm{~cm}, 24.33 \%$ at $20 \mathrm{~cm}$ and $24.58 \%$ at $30 \mathrm{~cm})$, but the differences were not statistically significant $(p>0.05)$.

No statistical difference was observed between bare soil thesis at all depths and fallow thesis at $10 \mathrm{~cm}(\mathrm{p}>0.05)$, while other comparisons are all different between them.

During the winter the soil humidity at a depth of $20 \mathrm{~cm}$ did not differ from that at 30 $\mathrm{cm}$, during the summer the three depths could not be distinguished from each other $(\mathrm{p}=1)$.

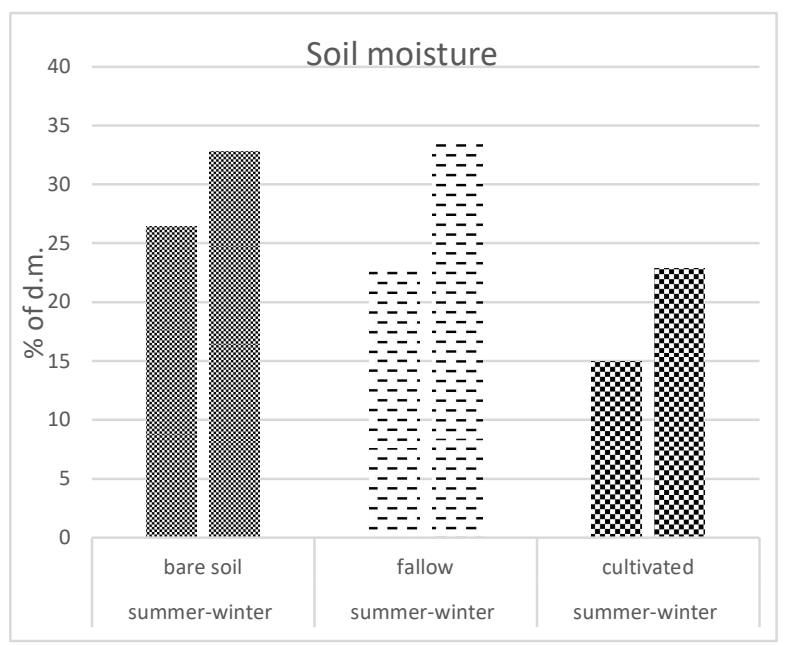

Figure 1. The soil moisture averages of summer and winter seasons in different theses.

The variability of the water content depended on the soil conditions: the bare soil showed a lower variability due to the absence of vegetation that would remove more moisture in the absence of rain, but at the same time it had a good percentage of moisture compared to the other two theses due to the presence of organic residues of removed turf, they tended to retain moisture in the soil. It was known that the organic substance on the one hand retains moisture and on the other hand allows a better flow of excess water in soil. It was known that the "variability of water content in the soil treated with compost was smaller than the one recorded for the areas with nitrogenous fertilizer, at 5 and $10 \mathrm{~cm}$ of depth" (Napolitano, 2011). Fallow presented greater variability, because the presence of organic residues retained moisture but on the other it presented absorption by the turf which subtracted water from the soil in the absence of rain. The lower moisture content of the cultivated soil was due to its low organic matter content caused by the oxidation of repeated tillage, so it had less ability to be a reservoir for water and to have a better soil structure.

The trend of humidity during the months showed a lower water content from May to August, obviously a little different in the years due to the seasonal trend; from the Figure 2 , the same months had different humidity in different theses. 


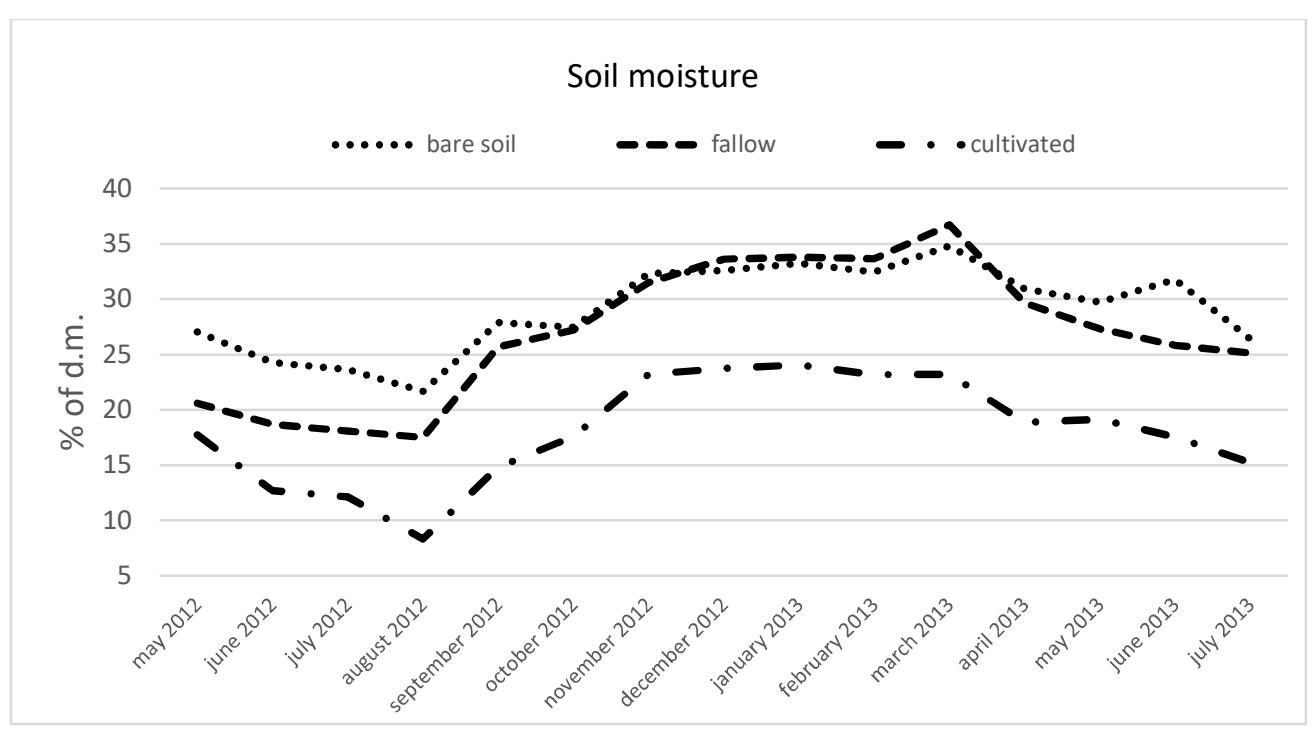

Figure 2. The moisture values during different months.

The nitrate determinations in the different theses had shown that the cultivated had lower values than the other two theses (Figure 3 ) and comparisons were all statistically significant with a $\mathrm{p}=0.0000$.

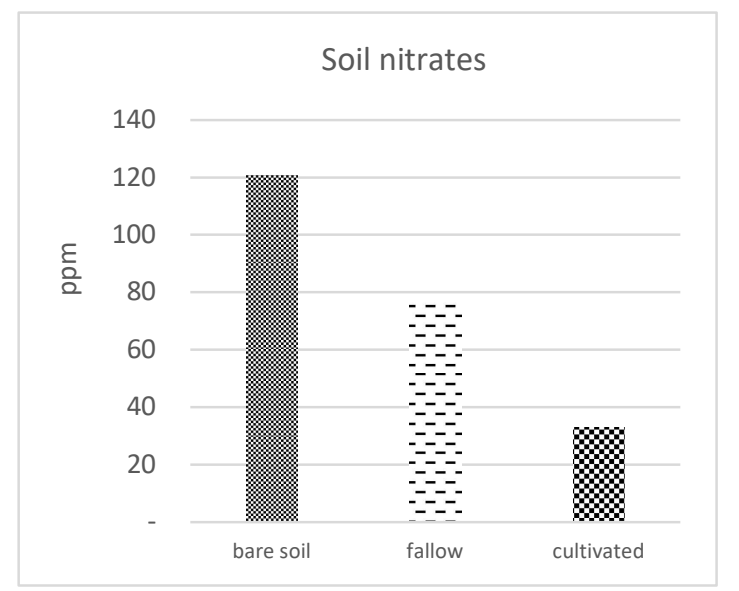

Figure 3. The soil nitrate averages in three theses.

The nitrate values showed a reduction for the three depths going from 10 to $30 \mathrm{~cm}$ (Figure 4), statistically significant ( $\mathrm{p}=0.0000, \mathrm{p}=0.0000$ and $\mathrm{p}=0.0219$ ). 


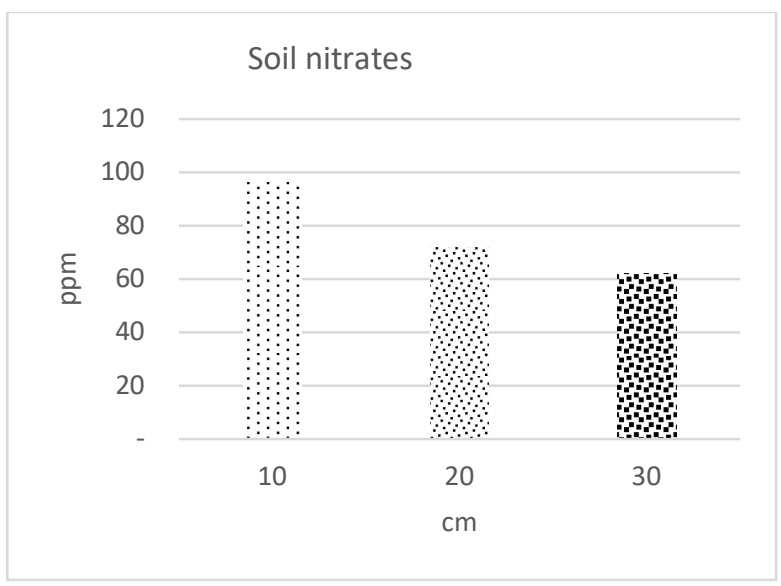

Figure 4. The soil nitrate averages at three depths.

The differences between winter and summer revealed nitrates low levels during the winter season with an average of $50.92 \mathrm{ppm}$ and an average of $94.52 \mathrm{ppm}$ during summer.

Observing the three separate theses, in two seasons, a different behavior was showed (Figure 5): the bare soil showed a larger nitrate explosion during the summer than the other theses. During the summer there was a greater production of nitrates because the microorganisms were mineralizing the organic residues of the remaining roots and the nitrates produced were not absorbed by the vegetation.

In the figure 5 the winter fallow did not differ statistically from the summer fallow $(p=1)$ and from winter bare soil $(p=0.0678)$. During the summer comparisons between the theses presented highly significant differences $(p=0.0000)$.

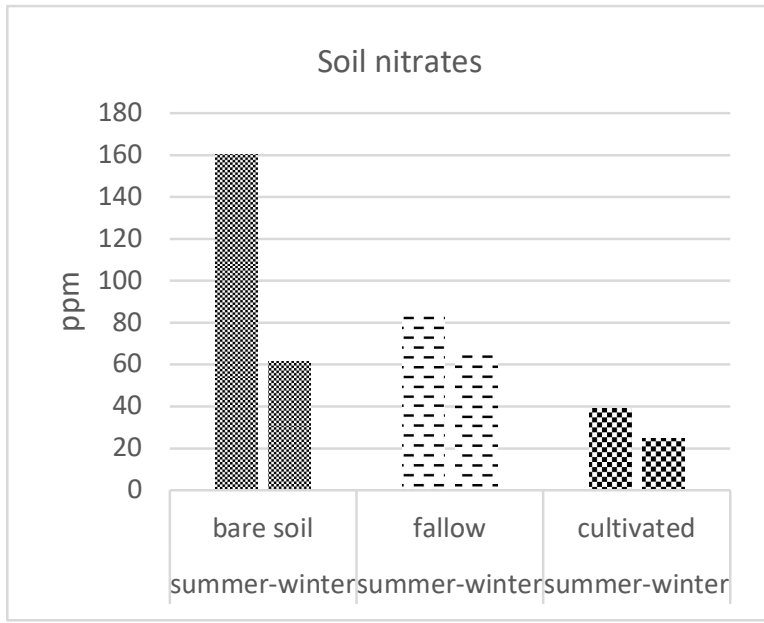

Figure 5. The soil nitrate averages in summer and winter seasons in all theses. .

As can be seen from Figure 6 in the different months there were different averages, the months from May to October 2012 and from April to July 2013, named summer months, presented high averages of nitrates while the months from November 2012 to March 2013, named winter months, had low values. The low values were due to immobilization by soil bacteria and other physico-chemical dynamics. In the summer months the soil had the prevalence of processes that increased mineral nitrogen available by plants compared to those that determine the loss of nitrogen in root zone, consequently we had in all theses a natural explosion in nitrates production during summer season at different levels. The statistical comparison between the months indicated a similarity within the 
periods of each season, even if there was a similarity between some winter months with the first summer months of first year examined.

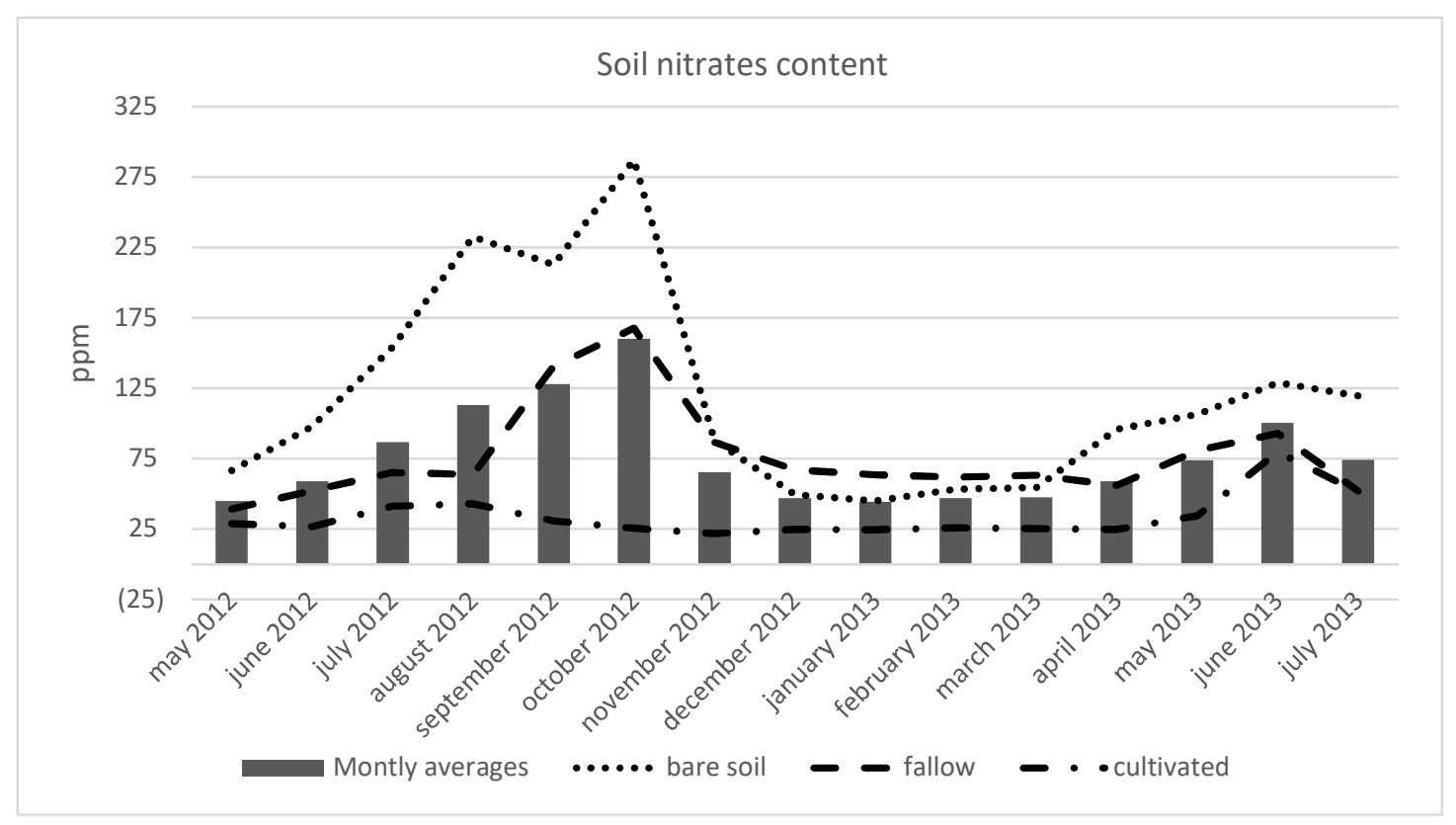

Figure 6. Monthly averages of soil nitrates content during the years 2012-2013.

Regarding organic matter monitored in the three theses and expressed as Abs at 275 $\mathrm{nm}$ (figure 7), the cultivated showed lower content of organic substance followed by bare soil and fallow, with significant statistical differences $(p=0.0000)$.

The presence of vegetation contributed to keeping a certain amount of organic substance in the fallow to as well as in the bare soil theses; although to a lesser extent, the radical residues of the removed grass turf in bare soil had left organic residues in the soil. The cultivated soil had a lower content of organic matter being the soil repeatedly ventilated by tillage (Figure 7). The continuous oxidation of the soil tended to consume the organic matter present over time.

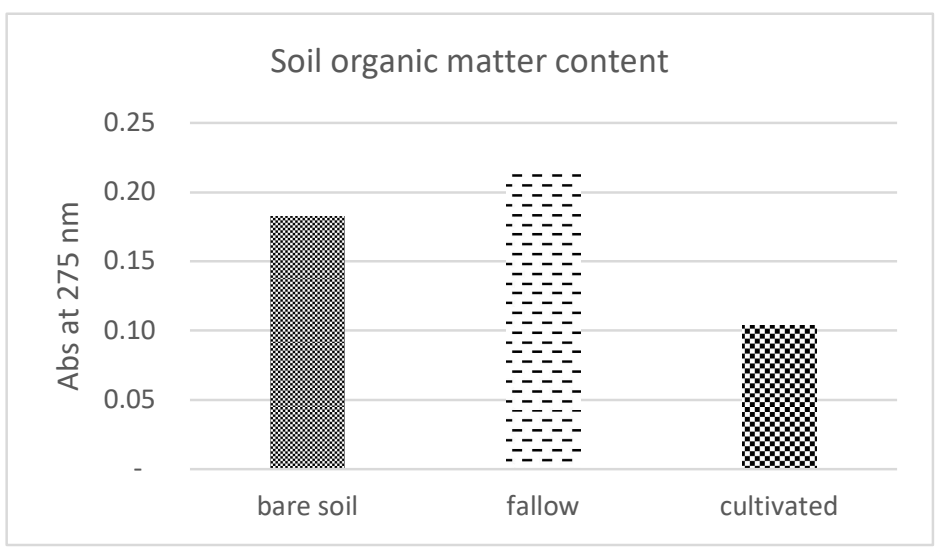

Figure 7. Soil organic matter content in different theses.

Keeping separate the theses in the two seasons, it emerged that there was no statistical difference in the comparisons within each thesis between summer and winter, so this 
parameter seemed to be more stable throughout the year than the other parameters examined in this study (figure 8).

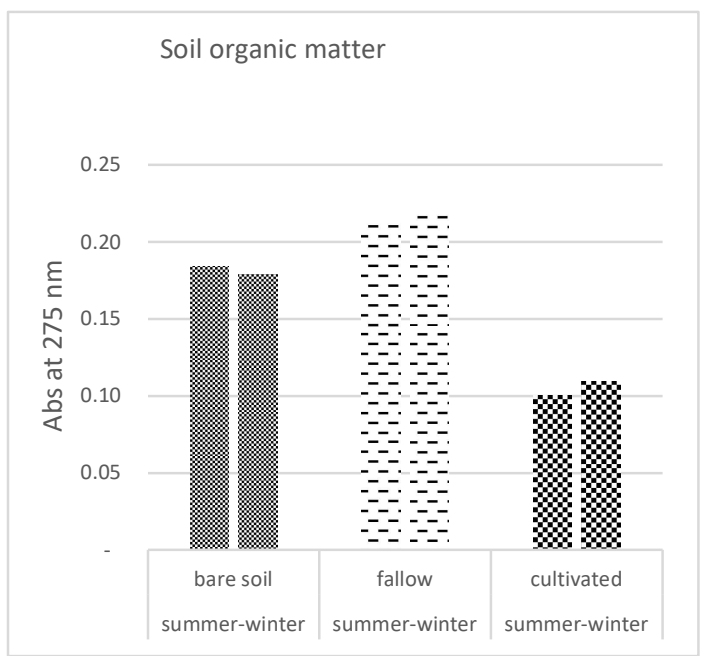

Figure 8. Soil organic matter content in theses.

Indeed, the comparison between summer and winter seasons (figure 9) was statistically significant $(\mathrm{p}=0.0027)$.

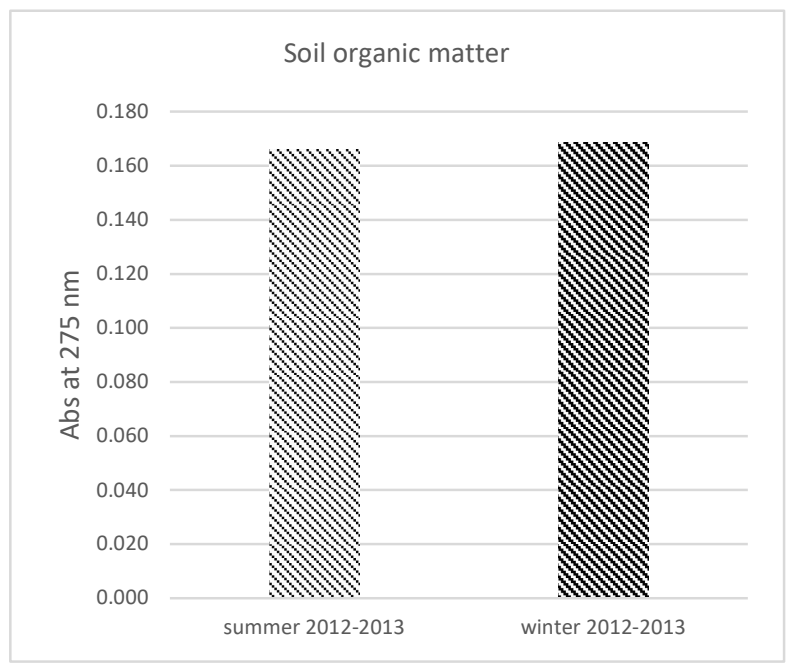

Figure 9. Soil organic matter in summer and winter seasons.

The values of organic matter content showed a reduction in the averages with increasing depth (Figure 10) and, statistically, they were significant ( $p=0.0000)$. Comparing the organic substance soil content at the three depths in the two seasons (Figure 11), it emerged that within the same depth there was no difference between the seasons. 


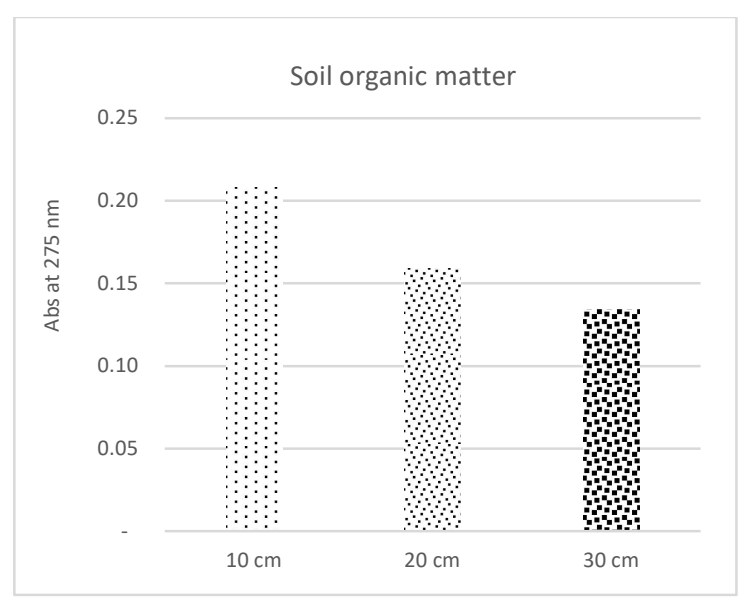

Figure 10. Soil organic matter content at three depths.

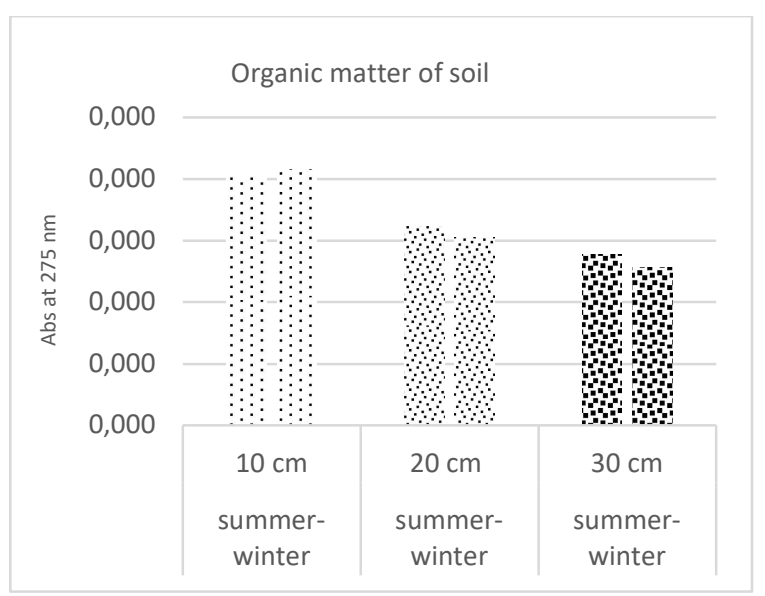

Figure 11. Organic matter of soil at all depths in summer and winter seasons

During the months there was some variability similar in all theses (Figure 12) although at different levels, a decrease in the organic material was observed in the months of December, January, May and June in all theses simultaneously. Probably this behavior of the organic matter was due to the different trend of the meteorological parameters during the months of year. 


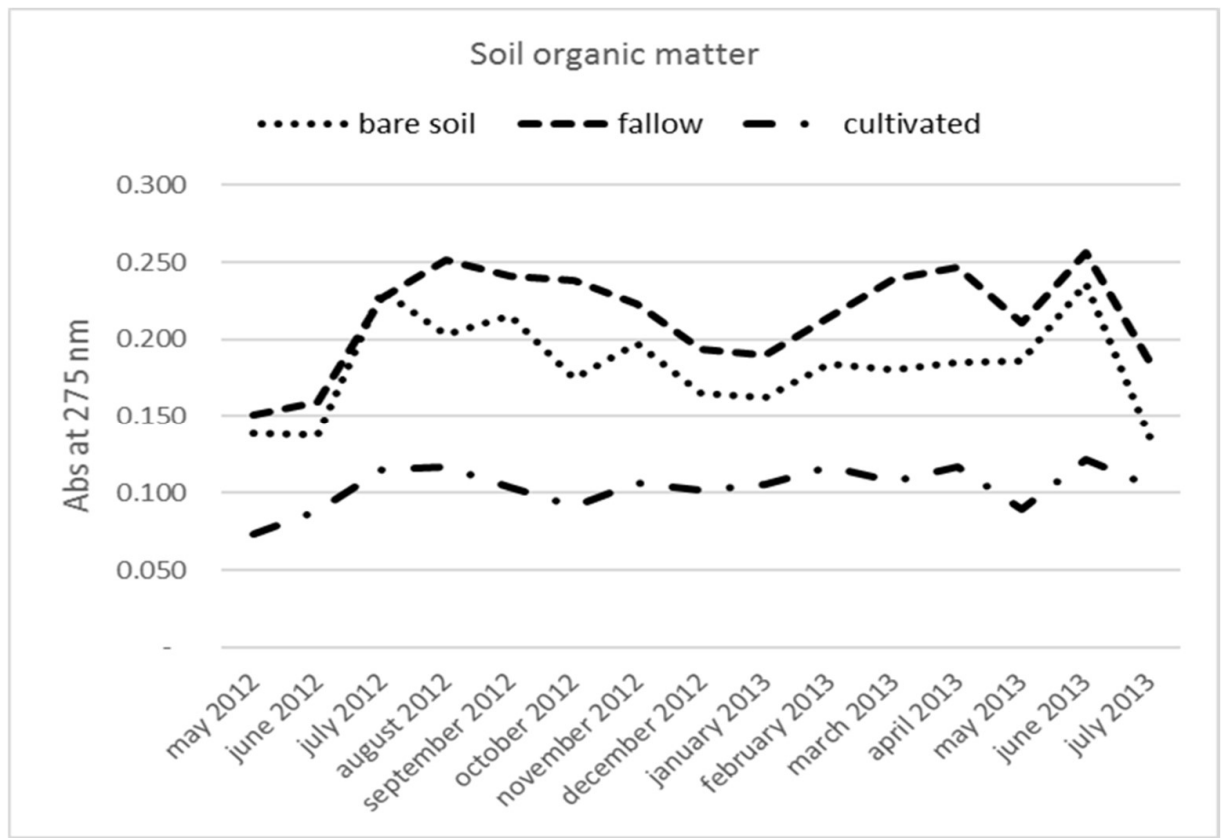

Figure 12. Soil organic matter content in different months.

From the study of the square, nitrate values showed greater variability in space $(p=5.598$ e-15) than in time $(p=1.85$ e-06), although significant comparisons were few. Humidity had shown similar variability in space $(\mathrm{p}=2.2 \mathrm{e}-16)$ and in time $(2.2 \mathrm{e}-16)$. Finally, the organic matter had shown greater variability over time $(p=0)$ than space $(p=0.0098)$.

For the transept, we observed a spatial variability (humidity with $p=0.0001158$, nitrates with $p=0.01678$ and organic matter with $p=0.00236$ ) that did not fully emerge in the square. This due to the small size of the square's sampling area.

In figure 13,14 and 15 we find experimental variogram of humidity, nitrates and organic matter, validated by Monte Carlo test: only some lag of humidity (up to 10 lag or 5 $\mathrm{m}$ ) and organic matter (up to 15 lag or $7.5 \mathrm{~m}$ ) were autocorrelated; nitrate values were not autocorrelated and showed a cyclical trend. 


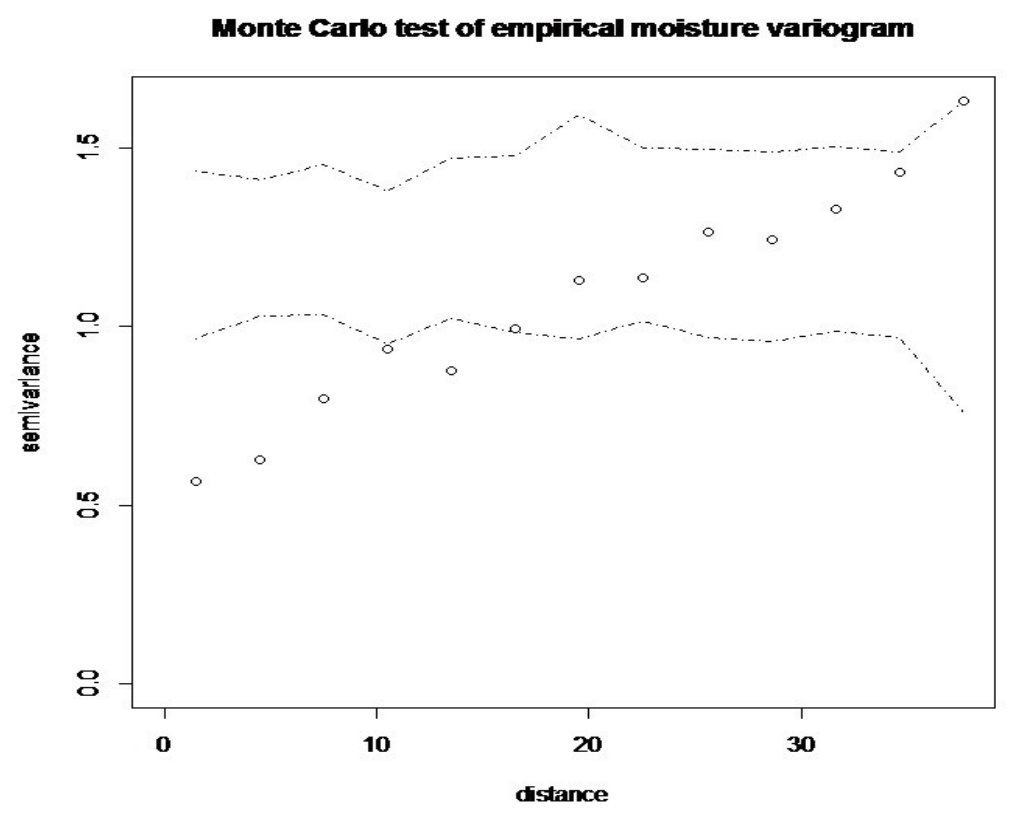

Figure 13. Envelop Monte Carlo (dotted lines) of the empirical variogram (points) of humidity. Since not all points lie within the envelope it is concluded that spatial dependence influences significantly the process.

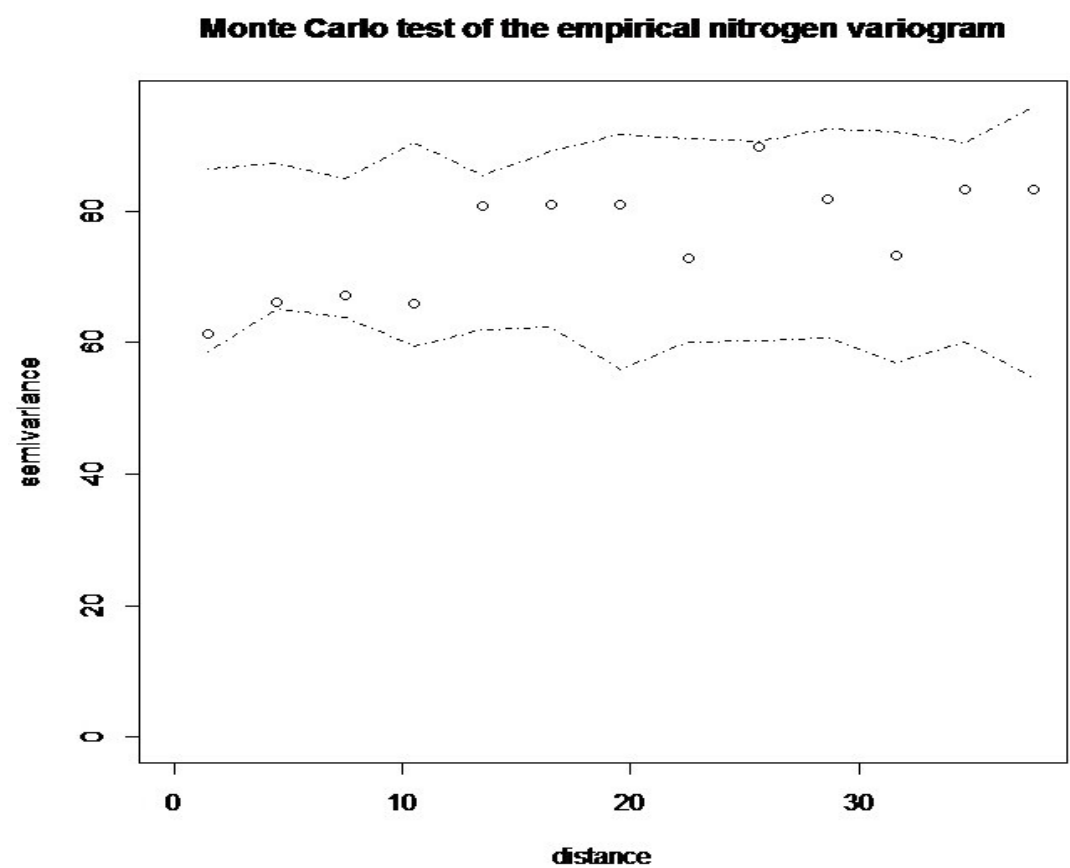

Figure 14. Experimental variogram of nitrates, in it all points lie within the envelope it is concluded that spatial dependence does not influence significantly the process. 
Montecarlo test of empirical variogram of organic matter

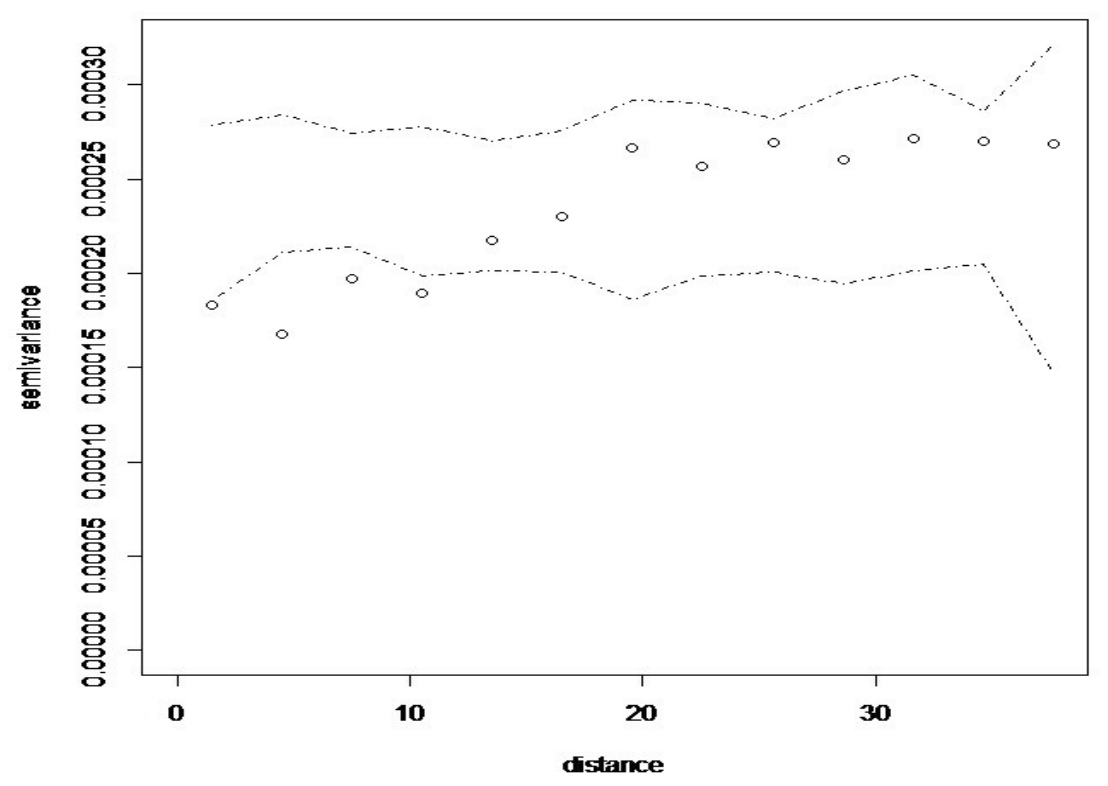

Figure 15. Envelop Monte Carlo (dotted lines) of the empirical variogram (points) of organic matter. Since not all points lie within the envelope it is concluded that spatial dependence influences significantly the process.

\section{Discussion and Conclusions}

This study has shown that the differences between the three parameters studied (humidity, nitrates and organic substance) in the three theses were all statistically different from each other. Nitrates and humidity ranged with the depth of the soil (at least up to 30 $\mathrm{cm}$ ) and the season. The humidity increased in the theses that presented organic plant residues and in the winter season. Many environmental factors interfered with nitrogen mineralization, in fact it was known that $\mathrm{N}$ mineralization is affected not only by soil moisture but also by many other factors such as changes in soil microbial communities, temperature, litter input and soil organic matter (Abera et al., 2012). A study in laboratory incubation tests it was found that after some specific times of incubation, increases in soil moisture content enhanced $\mathrm{N}$ mineralization in in the loamy sand and loam soils (Kasetsart J., 2005)

Nitrates had, in our observations, a high value in bare soil and uncultivated theses rich in organic matter, nitrates were high in the summer months while maintaining different levels of concentration in the theses. These observations are confirmed by Crohn and University of California. Cron said that the immediate availability of nitrogen was greater in summer than in winter, the mineralization of available nitrogen should always be monitored to avoid excesses with respect to crop needs and the mineralization was faster in warm and moist soils and slower in soils that were cold or dry (Crohn D.,2004)

The University of California reported that mineralization was faster in hot and humid soils and slower in cold or dry soils and nitrogen mineralization can occur when the crop is small or absent (e.g. after summer harvest or before the vegetative restart); the mineralization rate of the organic matter was influenced by various factors such as the presence of organic matter, the structure of the soil, the intensity of the soil tillage and other factors, so it was difficult to gauge (web site 2009. University of California).

The presence of nitrates depended, in our study, on the presence of cultivation or organic residues. 
In fact previous studies said that all plant covers have a «nitrate trapping » effect and that the longer the interval between the destruction of the cover crop and the planting of the following crop, the larger will be the contribution of mineral nitrogen from the cover crop residues to the end of winter. (Cohan J.P. 2009)

The organic substance showed a lower concentration during the summer. The organic matter tended to be less variable during the year, there was a decrease in the months of December, January, May and June. Many studies had been done on the effects of drying and rewetting on soil processes, particularly on respiration (e.g. Franzluebbers et al., 2000; Mamilov and Dilly, 2002) , on N mineralization (Fierer and Schimel, 2002; Mikha et al., 2005), on biomass growth and on mobilization and metabolization otherwise unavailable soil carbon (Xiang S.R,2008).The climate change leads to an intensification of the hydrological cycle, an increase of evapotranspiration and drought in the soil combined with more intense storms (Milly et al., 2002; Huntington, 2006).

Our test showed a spatial variability in all the parameters; the nitrates and the humidity had greater spatial and temporal variability with respect to the organic substance. The nitrates of the transept studied by the Monte Carlo test did not indicate spatial autocorrelation with respect to the other two parameters (it did discordant with previous research); organic matter and humidity showed autocorrelation up to 10-15 lag corresponding to the 5-7.5 m distance between the samples. In conclusion we can say that there was a certain spatial and temporal variability in all the variables. This reason makes it desirable to intervene with Precision Agriculture and sustainable management practices, so that we can identify uniform areas (for the characteristics of the soil) and uniform seasonal periods; and how it was said "it might be the key to a successful cultivation in Mediterranean environment "(Basso et al., 2011).

\section{References}

Abera G.,Wolde-meskel E., Beyene S., and R. Bakken L.2012. Nitrogen Mineralization Dynamics under Different Moisture Regimes in Tropical Soils. International Journal of Soil Science, 2012, 132-145.

Agehara, S., Warncke, D. D. Soil moisture and temperature effects on nitrogen release from organic nitrogen sources. Soil Sci. Soc. Am. J., 2005, 1844-1855.

Albrektienè R., Rimeika M., Zalieckienè E., Valentinas Šaulys V., Zagorskis A., Determination of Organic Matter by UV Absorption inthe Ground Water. Journal of Environmental Engineering and Landscape Management, 2012, 163-167.

Basile A., Terribile F., In: Ricerca sull'inquinamento da nitrati nei suoli campani. Un approccio modellistico nella gestione agroambientale. Reg. Campania, CNR-ISAFOM, Università di Napoli “Federico II”, Dip. Agronomia. 2008.

Basso, B., Ritchie, J.T., Cammarano, D., Sartori, L. A strategic and tactical management approach to select optimal N fertilizer rates for wheat in a spatially variable field. Eur. J. Agron., 2011, 215-222.

Benedetti A., Sebastiani G. “Determination of potentially mineralizable nitrogen in agricultural soil. Biol Fertil, 1996, 114-120.

Brady, N.C., Weil, R.R. Soil Colloids: Seat of Soil Chemical and Physical Acidity. In The Nature and Properties of Soils; Brady, N.C., Weil, R.R., Eds.; Pearson Education Inc.: Upper Saddle River, NJ, USA; 2008, 311-358.

Cohan J.P. Effects of the mineral nitrogen content of the soil Capacity of cover crops to trap nitrate and to contribute to the nitrogen nutrition of the following crop Selected Papers from ARVALIS - Institut du végétal - $\mathrm{N}^{\circ} 9$ Cover crops From Perspectives Agricoles $n^{\circ}$ 357. 2009.

Diacono M., Castrignanò A., Troccoli A., De Benedetto D., Basso B., Rubino P. Spatial and temporal variability of wheat grain yield and quality in a Mediterranean environment: A multivariate geostatistical approach. Field Crops Research, $2012,49-62$.

Delin, S., Lindén, B. Relations between net nitrogen mineralization and soil characteristics within an arable field. Acta Agric. Scand. B, 2002, 78-85.

Dharmakeerthi, R. S., Kay, B. D., and Beauchamp, E. G. 2005. Factors contributing to changes in plant available nitrogen across a variable landscape. Soil Sci. Soc. Am. J., 2005, 453-462.

Duxbury, J. M., Lauren, J. G., Fruci, J. R. Measurement of the biologically active soil nitrogen fraction by a $15 \mathrm{~N}$ technique. Agric. Ecosyst. Environ., 1991, 121-129.

Fierer, N., Schimel, J.P., Effects of drying-rewetting frequency on soil carbon and nitrogen transformations. Soil Biology \& Biochemistry, 2002, 777-787.

Franzluebbers, A., Haney, R., Honeycutt, C., Schomberg, H., Hons, F., Flush of carbon dioxide following rewetting of dried soil relates to active organic pools. Soil Science Society of America Journal, 2000, 613-623.

Gregorich, E. G., Carter, M. R., Angers, D. A., Monreal, C. M., Ellert, B. H. Towards a minimum data set to assess soil organic matter quality in agricultural soils. Can. J. Soil Sci., 1994, 367-385. 
Haynes, R. J. Labile organic matter fractions as central components of the quality of agricultural soils: An overview. Adv. Agron., 2005, 221-268.

Huntington T. G., Evidence for intensification of the global water cycle: Review and synthesis Journal of Hydrology, $2006,83-95$.

Kasetsart, J. Influence of Soil Moisture Content on Time Courses of Nitrogen Mineralization and Immobilization Caused by Applications of Different Plant Residue to Soils with Different Textures. Nat. Sci., 2005, $24-33$

Kemmitt, S. J., Lanyon, C. V., Waite, I. S., Wen, Q., Addiscott, T. M., Bird, N. R. A., O’Donnell, A. G., Brookes, P. C. Mineralization of native soil organic matter is not regulated by the size, activity or composition of the soil microbial biomass - A new perspective. Soil Biol. Biochem., 2008, 61-73.

Liu C.-W., Sung, Y., Chen, B.-C., Lai, H.-Y. Effects of Nitrogen Fertilizers on the Growth and Nitrate Content of Lettuce (Lactuca sativa L.). International Journal of Environmental Research and Public Health, 2014, 4427-4440.

Luce M, Whalen J K, Ziadi N, Zebarth B J. Nitrogen dynamics and indices to predict soil nitrogen supply in humid temperate soils. Adv. Agron., 2011, 55-102.

Mamilov, A.S., Dilly, O.A. Soil microbial eco-physiology as affected by shortterm variations in environmental conditions. Soil Biology \& Biochemistry, 2002, 1283-1290.

Mensinga, T.T.; Speijers, G.J.; Meulenbelt, J. Health implications of exposure to environmental nitrogenous compounds. Toxicol. Rev., 2003, 41-51.

Merafina P. Monitoraggio della dinamica dei nitrati nel mezzo insaturo in un'area vulnerabile della provincia di Parma e applicazione del modello di simulazione CropSyst. Università degli Studi di Parma, Italy, 2003.

Milly, P., Wetherald, R., Dunne, K. et al. Increasing risk of great floods in a changing climate. Nature, 2002, 514-517.

Mikha, M.M., Rice, C.W., Milliken, G.A. Carbon and nitrogen mineralization as affected by drying and wetting cycles. Soil Biology \& Biochemistry, 2005, 339-347.

Napolitano A., 2011. Analysis of some parameters related to the hydraulic infiltration of a silty-loam soil subjected to organic and mineral fertilizer systems. Italian Journal of Agronomy, 2011, e19.

Santamaria, P. Nitrate in vegetables: Toxicity, content, intake and EC regulation. J. Sci. Food Agr., 2006, 10-17.

Subbarao, G. V., Ito, O., Sahrawat, K. L., Berry, W. L., Nakahara, K., Ishikawa, T., Watanabe, T., Suenaga, K., Rondon, M., Rao, I. M. 2006. Scope and strategies for regulation of nitrification in agricultural systems-Challenges and opportunities. Crit. Rev. Plant Sci., 2006, 303-335.

Xiang S.R, Doyle A., Holden P.A., Joshua P. Schimel J.P. Drying and rewetting effects on C and N mineralization and microbial activity in surface and subsurface California grassland soils. Soil Biology \& Biochemistry, 2008, 2281-2289.

Websites

Crohn D.,2004 http://alfalfa.usdavis.edu . Nitrogen mineralization and its importance in organic waste recycling david crohn1abstract Proceedings, National Alfalfa Symposium, 13-5 December 2004, San Diego, CA, UC Cooperative Extension, University of California, Davis 95616.

http://manuremanagement.ucdavis.edu .Manure Nitrogen Mineralization. 2009. University of California Cooperative Extension Manure Technical Bulletin Series.

https://www.iris.sssup.it/retrieve/handle/11382/.306758/1104/7-Azoto ne terreno.pdf (7-Azoto nel terreno - Archivio della ricerca della Scuola Superiore ...)

Omodame M. 2012. Esercitazioni di statistica biomedica alcune note su R. Matteo Dell'Omodarme agosto 2012 oppure http://www.r-project.org

Nutrient Management Spear Program http://nmsp.css.cornell.edu 2009 